Child Abuse \& Neglect

Report of Empirical Research

Post-refereeing version

\title{
Interpersonal violence against children in sport in the Netherlands and Belgium
}

Tine Vertommen ${ }^{\mathrm{a}, \mathrm{b} *}$, Nicolette Schipper-van Veldhoven ${ }^{\mathrm{c}, \mathrm{d}}$, Kristien Wouters ${ }^{\mathrm{e}}$, Jarl Kampen ${ }^{\mathrm{f}, \mathrm{g}}$, Celia Brackenridge $^{\mathrm{h}}$, Daniel Rhind ${ }^{\mathrm{h}}$, Karel Neels ${ }^{\mathrm{i}}$, and Filip Van Den Eede ${ }^{\mathrm{a}, \mathrm{b}}$

a Collaborative Antwerp Psychiatric Research Institute (CAPRI), Faculty of Medicine and Health Sciences, University of Antwerp, Antwerp, Belgium;

${ }^{b}$ University Department of Psychiatry, Campus Antwerp University Hospital, Antwerp, Belgium;

c Netherlands Olympic Committee and Netherlands Sports Confederation (NOC*NSF), Arnhem, the Netherlands;

$d$ Research Centre Human Movement and Education, Windesheim University of Applied Sciences, Zwolle, the Netherlands;

e Department of Scientific Coordination and Biostatistics, Antwerp University Hospital, Antwerp, Belgium;

$f \quad$ StatUA, University of Antwerp, Antwerp, Belgium;

$g$ Research Methodology Group, Wageningen University, the Netherlands;

$h$ Centre for Sport, Health and Wellbeing, Brunel University, London, United Kingdom;

i Department of Sociology, University of Antwerp, Antwerp, Belgium

Software: Microsoft Word

Words abstract: 166

Words text: $+/-5500$

Pages: 33

Tables: 6

Figures: 1

Appendix: 1

\section{Acknowledgements}

This study is funded by the Netherlands Olympic Committee*Netherlands Sports Confederations (NOC*NSF), and by the Department Culture, Youth, Sport, and Media of the Flemish administration (2012/mvs/1).

* Corresponding author: University of Antwerp, CAPRI, Campus Drie Eiken, Universiteitsplein 1, 2610 Antwerp, Belgium. Email: Tine.Vertommen@uantwerpen.be 


\begin{abstract}
The current article reports on the first large-scale prevalence study on interpersonal violence against children in sport in the Netherlands and Belgium. Using a dedicated online questionnaire, over 4,000 adults prescreened on having participated in organized sport before the age of 18 were surveyed as to their experiences with childhood psychological, physical, and sexual violence while playing sports. Being the first of its kind in the Netherlands and Belgium, our study has a sufficiently large sample taken from a comparatively general population, with a balanced gender ratio and wide variety in socio-demographic characteristics. The survey showed that $38 \%$ of all respondents reported experiences with psychological violence, $11 \%$ with physical violence, and $14 \%$ with sexual violence. Ethnic minority, lesbian/gay/bisexual (LGB) and disabled athletes, and those competing at the international level report significantly more experiences of interpersonal violence in sport. The results are consistent with rates obtained outside sport, underscoring the need for more research on interventions and systematic follow-ups, to minimize these negative experiences in youth sport.
\end{abstract}

Keywords: Prevalence; Child Abuse; Harassment; Maltreatment; Unwanted Behavior; Organized Sport

\title{
Introduction
}

Interpersonal violence (IV) in sport is an understudied phenomenon. Indeed, it is not customary to dwell on the negative sides of sport, which is traditionally viewed as a social good. Policy makers have been more preoccupied with making sport available (the sport-for-all doctrine) and injury-free than making it safe from interpersonal violence such as harassment and abuse (Schipper-van 
Veldhoven, 2012). Competitive sport is characterized by unique structures and cultures, a high tolerance of random incidents of physical violence and injuries as being part of the "rough and tumble" of the game, asymmetrical power relationships between coaches and athletes, the maledominated gender ratio, and the sports culture often being associated with authoritarian leadership, the often-required physical contact, the reward structures, and participation at an early age (Alexander, Stafford, \& Lewis, 2011; Brackenridge, 2010; Cense \& Brackenridge, 2001; Kirby, Greaves, \& Hankivsky, 2000). These characteristics suggest that sport is a conducive climate for IV against child athletes. Still, very few people expect sport to be associated with IV. As it is one of the responsibilities of leaders in organized sport to create a safe climate, a better understanding of the nature and frequency of occurrence of IV in youth sport is essential. The current study is the first large-scale quantitative analysis of the prevalence (i.e. the proportion of a population that has a specific characteristic at a given time) of IV among young athletes in the Netherlands and Belgium.

\section{Prevalence research}

There is a paucity of empirical evidence of IV against children in sport. The first quantitative studies in this field focused on unwanted sexual experiences among female athletes of various ages and found the prevalence of sexual harassment and abuse to vary between $2 \%$ and $50 \%$ (Fasting, Chroni, Hervik, \& Knorre, 2011; Kirby et al., 2000; Leahy, Pretty, \& Tenenbaum, 2002). Comparison of such studies is difficult because of the different definitions and research approaches they adopted. Nonetheless, recurrent findings are that risks are higher for girls and women than they are for boys and men, and more so for athletes performing at the elite rather than the recreational level (Fasting, Brackenridge, \& Sundgot-Borgen, 2003; Leahy et al., 2002). 
The focus on sexual violence in sport has recently widened to include other types of IV, with some (mostly qualitative) studies investigating emotional abuse, overtraining, physical punishment, hazing, bullying, and pressurization of young athletes (Baar \& Wubbels, 2013; Gervis \& Dunn, 2004; Stafford \& Fry, 2013; Stirling, Bridges, Cruz, \& Mountjoy, 2011; Stirling \& Kerr, 2012; Tiessen-Raaphorst \& Breedveld, 2007). In the United Kingdom, Alexander and colleagues (2011) recorded prevalence estimates of $75 \%$ for emotional harm and $24 \%$ for physical harm in athletes under the age of 16 . However, the study suffered from a very low response rate (under $1 \%$ ) and a potential selection bias can therefore not be excluded. A Dutch study on unwanted behavior in sport that gauged verbal, physical, and sexual violence (Tiessen-Raaphorst, Lucassen, van den Dool, \& van Kalmthout, 2008) revealed that 1 in 5 respondents aged 12 years or over reported having been a victim $(11 \%)$ or a witness of unwanted behaviors including verbal $(12 \%)$ or physical aggression (6\%), and sexual harassment (1\%). More recent Dutch data (Romijn, van Kalmthout, Breedveld, \& Lucassen, 2013) shows that nearly 4 in 10 of those who regularly participate in organized sport experience or witness unwanted behavior. To date, reliable prevalence rates for psychological and physical violence in organized youth sport are not available.

\section{Study purpose}

The main objective of the present article is to assess the prevalence of retrospectively selfreported IV in organized youth sport in Flanders and the Netherlands, while also considering differences between male and female, and their current ages.

Secondly, it is the aim to compare prevalence estimates in Flanders and the Netherlands. Shortly after a high profile case of sexual abuse in Dutch sport in 1996, the sport authorities in the Netherlands effected a Prevention of Sexual Harassment in Sport policy, which would later be 
incorporated into a comprehensive Safer Sports Climate program (Schipper - van Veldhoven, Vertommen, \& Vloet, 2014). Flanders, the Dutch-speaking part of the federal state of Belgium, on the other hand, only recently took action by implementing a safeguarding policy in sport (Vertommen, Tolleneer, Maebe, \& De Martelaer, 2014). While it is not the purpose of this study to evaluate the efficacy of the Dutch prevention system, this difference in the timing of prevention strategies underscores the relevance of a comparison of the Flemish and Dutch situation.

The third objective of this study is to focus on potentially risk-increasing factors such as sexual orientation, ethnicity, disability, and highest performance level. While there is no strong evidence available from studies in sport, the majority of studies in a general population indicate a higher prevalence of IV in minority groups consisting of LGB, immigrants and people with disabilities (Balsam, Rothblum, \& Beauchaine, 2005; Friedman et al., 2011; Hussey, Chang, \& Kotch, 2006; Jones et al., 2012; Putnam, 2003). Sport demands the most of its elite performers. International youth athletes invest an immense amount of time, money, energy in their sport, and have much more to lose. This makes them more vulnerable for exposure to IV in a sports context. Several studies have found elite athletes to be at higher risk of experiencing non-accidental violence in sport (Alexander et al. 2011, Fasting et al. 2003, Leahy et al. 2002).

\section{Methods}

\section{Definitions}

Violence is a contested term and has numerous definitions. Operationalizations of the concepts violence, maltreatment, and abuse vary worldwide, which complicates the interpretation and comparison of prevalence rates across studies. For our study we adopted the definition of violence as documented in article 19 of the Convention on the Rights of the Child (United Nations, 1989): "[..] all forms of physical or mental violence, injury and abuse, neglect or negligent treatment, 
maltreatment or exploitation, including sexual abuse while in the care of parent(s), legal guardian(s) or any other person who has the care of the child".

The term violence is conceptually and functionally related (Brackenridge, 2010) to the term abuse but comprises a wider range of behaviors that are not always or necessarily understood as abusive (e.g., harassment, peer-to-peer bullying, and verbal intimidation) (Krug, Mercy, Dahlberg, \& Zwi, 2002; United Nations, 2006). One might question our decision to apply such a broad definition of violence, containing milder forms such as whistling, glancing, and teasing. The United Nations Committee on the Rights of the Child, however, states the following on this issue: "All forms of violence against children, however light, are unacceptable. [...] Frequency, severity of harm and intent to harm are not prerequisites for the definitions of violence. State parties may refer to such factors in intervention strategies in order to allow proportional responses in the best interests of the child, but definitions must in no way erode the child's absolute right to human dignity and physical and psychological integrity by describing some forms of violence as legally and/or socially acceptable." (2011, p. 8)

When studying IV in sport, one needs to distinguish behavior deemed to be a normal part of the game from that considered to overstep the ethical mark (Brackenridge, 2010), i.e. deliberate or nonaccidental IV. Accordingly, violence occurring within the bounds of prescribed constitutive rules is not considered in this study.

We define organized sport as every recreational or competitive sporting activity that is voluntary, takes place within the context of a club or organization outside the school curriculum, and involves an element of training or instruction by an adult, including sport camps and organized extracurricular sporting activities at school but excluding physical education (PE lessons) and informal physical activities (e.g., street soccer games, walking the dog, and gardening). 


\section{The IViS questionnaire}

Currently, there is no validated international questionnaire on IV against children in sport. Alexander et al. (2011) used an informal index of possible negative and harmful experiences children might face in sport, which we used as a basis for our survey questionnaire. Comparing the Alexander et al. (2011) items with internationally validated clinical ACE inventories (in general), such as Felitti et al.'s ACE questionnaire (1998) and Berstein et al.'s Childhood Trauma Questionnaire (1994), we found their index to show good face and content validity, with all the relevant components of sport-related childhood trauma being represented, as well as the 16 main forms of abuse, neglect, and violence in competitive sports as listed by David (2004, p. 56). We have maintained the subdivisions of psychological, physical, and sexual IV but omitted the items on self-harm, organized abuse, drug use, and body image. The word harm was not adopted in order to preserve neutrality. The order and wording of some items was modified slightly, some items were split or merged, and a classification method was added (cf. infra). The questionnaire was then translated into Dutch and tested for compatibility with the Flemish language (the dialect of Dutch spoken in Flanders). Back-translation was performed by a certified translator. Comparison with Alexander et al.'s original questionnaire (2011) revealed no substantive differences.

The resultant questionnaire consisted of four sections, starting with a demographic and descriptive section inquiring into the respondents' sport career up until the age of 18, where they could indicate up to five different sports (from a list of the 72 most popular organized sports in the Netherlands and Flanders) together with the highest level achieved in each, and their overall impression of their childhood sport experiences. The next three sections probed the respondents' childhood experiences while playing sports: 14 items on psychological violence, comprising, among other types, aggressive verbal intimidation, exaggerated negative comments on performance or body, threats, and neglect, 10 items on physical violence and forced overtraining, and 17 items on 
sexual violence including sexual harassment and abuse. To minimize underreporting, it is important to use explicit questions that cover the full range of violence experiences (Hamby \& Koss, 2003). Rather than using a predetermined definition of IV, a set of detailed, personalized items on experiences involving IV were presented, for instance "you were being touched during training in a way that made you uneasy / feel uncomfortable", "you were criticized or threatened because you did not want to participate in training sessions or matches/competitions"; for further examples, see Appendix A.

The first (offline) version of the Interpersonal Violence against Children in Sport (IViS) was pretested by 40 Dutch and Flemish professionals simulating to be childhood victims of IV in sport who also completed a feedback form on its content, language, duration, and layout. Taking into account the findings of meta-research on violence, victims' reports on the impact of data collection methods on findings, and the method preferred by respondents (DiLillo, DeGue, Kras, Di LoretoColgan, \& Nash, 2006; Rosenbaum \& Langhinrichsen-Rohling, 2006; Rosenbaum, Rabenhorst, Reddy, Fleming, \& Howells, 2006), we opted for a computer-administered format using Confirmit software. This online version was then piloted in the target population. The trial included 487 Flemish and Dutch adult respondents having played organized sport before the age of 18 years and showed a fluent screening process, leading to minor changes in the questionnaire structure, wording, routing, and filtering. The prevalence rates we obtained (i.e., 32\% for psychological IV, $12 \%$ for physical IV, and $19 \%$ for sexual IV) were comparable to rates mentioned in the literature.

\section{Severity classification}

Being aware of the subjectivity of each self-reported retrospective experience and giving the inclusion of items on milder forms of violence, an additional severity assessment by independent 
experts was considered necessary. We know that quantitative research will never fully capture selfreported experiences but, by using expert severity assessments besides the respondents' frequency indications, we have attempted to structure the data as sensitively as possible. An expert group, consisting of 28 independent professionals in the field of child maltreatment policy, research and/or clinical practice in Flanders and the Netherlands, scored each of the 41 items from 1 to 3 (low, medium, high) indicating how they perceived the severity of the reported incident(s). Our classification system thus relied on both these expert severity ratings and the respondents' selfreported frequency scores (see Appendix A and Table 1). Note that there is no reason to assume correlations between the items (e.g., when you have been a victim of sexual assault in sport, it does not necessary mean you have also experienced verbal sexual harassment, sexual glances...). Therefore, instead of attempting to build a scale, the frequency (reported by respondents) and the severity (assessed by experts) of each item were the empirical input for constructing a measurement of the overall severity of the experience within each type of IV (psychological, physical, sexual).

\section{Insert Table 1 about here}

Items describing incidents with the lowest expert severity rating and respondent frequency scores were classified as mild IV, including one-time events with a medium severity rating, while those detailing events having received the lowest or a medium severity rating and a regularly/often score were categorized as moderate. Events the experts had rated as most severe were classified as severe regardless of their frequency.

\section{Procedure}


The prevalence of childhood sport-related IV was measured using a retrospective web-based survey of adult respondents aged between 18 and 50 years who had engaged in organized sports as a child (up to the age of 18). Sampling and data collection were performed by GfK, a market research company active in the Netherlands and Belgium (www.gfk.com) drawing on a longitudinal panel. The panel is a convenience sample of the Internet population in both countries. Panel members were invited to participate in the study by email. The briefing letter contained information on the content of the web survey, a link to an informative website about the methodology of the study, a directory of counselling services, and a hyperlink to the actual IViS questionnaire. Respondents could only proceed after agreeing with the informed consent request. Respondents were able to pause or terminate the survey at any point or stage. Approval for the research protocol was obtained from the Antwerp University Hospital ethics committee prior to the pilot study (file code 13/44/430).

\section{The sample}

After prescreening the Dutch panel members on their participation in youth sport, 4,751 panel members were invited to participate in the study. Within the 3-week fieldwork period, 2,755 (58\%) used the web-survey hyperlink. Of these, $346(12 \%)$ did not meet the inclusion criteria (18-50 years and active in organized sport before age 18), 84 did not provide their informed consent, while another 326 did not fully complete the questionnaire. All those were excluded from the study. With 1999 respondents having completed the questionnaire correctly after less than three weeks, the target number had been reached and the Dutch survey site was closed.

Inherent to a different way of panel organization in Flanders, the Flemish respondents were not prescreened on having participated in youth sport before the start of the study. In total, 16,863 
Flemish panel members were sampled to take part in the study. Of the 4,236 panel members in Flanders that activated the hyperlink during the time frame of the fieldwork, $1,750(41 \%)$ did not meet the inclusion criteria, 16 did not give their informed consent, while 426 failed to complete the survey. At the end of the fieldwork period, the data of 2,044 Flemish respondents were available for further analysis. In total, 4,043 respondents had been successfully recruited within three weeks.

\section{Statistical procedures}

The primary aim of this study was measuring the prevalence of IV in youth sport. To be able to assess a prevalence of $6 \%$ with a maximum precision of $3 \%$ at a significance level of 0.01 , and assuming random samples from the target populations, 2000 respondents in each country were required. Precision is defined here as the width of the $99 \%$ confidence interval (CI). The assumption of a $6 \%$ prevalence is based on the results for severe psychological, physical and/or sexual violence in the pilot study (Hintze, 2011).

To determine differences between subgroups, simple binary logistic regressions were used. ORs and 99\% CIs are reported. A multiple binary logistic regression model containing gender, ethnicity, current age group, highest sport level, sexual preference, disability, and country was built for each of the three IV types. Pairwise interactions were checked and included in the model if significant. Posthoc comparisons were made for the interaction terms included. Through backward elimination, we arrived at the most parsimonious model, with all main effects and interactions significant at alpha $<0.001$. The partial nonresponse was less than $1 \%$, so no additional adjustment was made. All statistical analyses were performed using IBM SPSS software version 22. 


\section{Results}

\section{Sociodemographic and sport characteristics of the study sample}

The sociodemographic characteristics of the respondents in the final sample for analysis are summarized in Table 2. The respondents, of whom 55\% were female, were recruited from all regions in Flanders and the Netherlands, from cities as well as rural areas, and their ages were evenly distributed between 18 and 50 years. As to level of education, $16 \%$ had received no or lower secondary education only, $42 \%$ had completed higher secondary/vocational education, and $42 \%$ had obtained a university degree (BA, MA/MSc, $\mathrm{PhD})$. Children's participation in Flemish cluborganized sports varied between 45 and $57 \%$ in the last three decades, whereby boys had somewhat higher participation rates than girls (Vandermeerschen, Vos, \& Scheerder, 2014). In the Netherlands, around $88 \%$ of 6-to-17-year olds regularly engaged in physical activities in 2013 , with equal participation rates for boys and girls (Collard \& Hoekman, 2012; Collard \& Pulles, 2014). Our study sample reflects the few characteristics that are known about the target population.

\section{Insert Table 2 about here}

Table 2 also provides an overview of the respondents' childhood sports background. The majority (69\%) had participated in more than one sport, with nearly all (97\%) having been active members of at least one club sport. Many had been active in informal sport groups, sport camps, or as members of commercial sports facilities (e.g., a gym/fitness club). The highest performance level achieved varied widely: almost a third of all respondents had played recreational sports only; the others had played at least one of the listed sports at the competitive level, ranging from local to international (3\%), while 5\% had participated in organized sport activities for disabled children, although the majority had not done so exclusively. 
Reported prevalence of IV in the overall sample

Table 3 gives an overview of the self-reported frequency of IV during the respondents' sports histories. Almost 38\% indicated at least one incident of psychological violence, $11 \%$ at least one event involving physical violence, while $14 \%$ had experienced sexual violence at least once.

\section{Insert Table 3 about here}

A total of 1,785 respondents (44\%) reported at least one experience with one of the three types of IV, 167 of whom (4\%) had experienced all three types. The set diagram in Figure 1 shows the proportions and relations for the various IV types. Of the respondents reporting physical or sexual violence, the majority ( $80 \%$ and $67 \%$, respectively) also reported at least one incident of psychological violence.

\section{Insert Figure 1 about here}

\section{Reported prevalence of IV according to country and gender}

In Table 4 the reports of IV are classified according to country, gender, current age, sexual preference, ethnicity, participation in disabled sports, and highest sporting achievement. We found no significant differences between Flemish and Dutch reports of psychological violence. For physical and sexual violence, however, the prevalence rates are significantly higher in Flanders (see Tables 4 and 5). Psychological violence shows no significant gender differences, but the rates for physical violence $(\mathrm{p}<.001)$ are higher in the male respondents while the female respondents reported higher rates of sexual violence $(\mathrm{p}<.001)($ Table 4 and 5$)$. 


\section{Reported prevalence of IV according to current age}

Experiences with physical and sexual violence did not differ among the four age groups: respondents having participated in sports in the 1970s, 1980s, 1990s, and 2000s reported similar rates for these IV types (see Table 5). The number of reports of psychological violence are, however, significantly lower in the older respondents, with the oldest group (playing sports in the 1970s and 1980s) reporting significantly fewer incidents (30\%) than the youngest group (playing sports in the 2000s; 46\%; $\mathrm{p}<.001)$ (see also Table 5).

\section{Insert Table 5 about here}

\section{Risk factors for IV in youth sport}

\section{Reported prevalence of IV higher in minority groups}

Table 4 also shows that the self-reported IV prevalence rates for the respondents from minority groups are significantly higher than those for the other subgroups. Except for psychological violence as experienced by respondents with a non-Flemish/Dutch background, the other IV rates are all significantly higher for the immigrant, lesbian/gay/bisexual (LGB) and disabled athletes than those recorded for the other respondents in our sample (for significance values, see Table 5). Finally, among those having participated in disabled sports, prevalence estimates are remarkably high for all three types of IV, with ORs up to 3 for physical violence (Table 5).

International elite athletes more at risk of IV

Looking at the highest level the respondents achieved in their sports, we note significantly increased IV prevalence rates among those having performed at the international level $(\mathrm{p}<.001)$. Except for the national level, all other levels showed higher ORs than those recorded for recreational sport only (all p-values $<.001)$. 
Having run simple and multiple logistic regressions on all relevant data (see Table 5), we found that current age, bisexuality, and international sport level are significant risk factors for psychological violence. As to physical violence, country (Flanders), gender (male), bisexuality, ethnic minority, disability, and international sport level had a significant impact on the reported prevalence, while the regression model of sexual violence showed country (Flanders), gender (female), ethnic minority, disability, international sport level, and the interaction terms (bisexual and homosexual men) to be significant predictors.

\section{Severity classification}

Applying our severity classification system to the resulting data, we can conclude that $9 \%$ of all respondents experienced severe psychological violence, $8 \%$ severe physical violence, and 5\% severe sexual violence (Table 6). The majority of respondents reporting psychological violence had experienced moderate forms (17\%). Notably, the proportion of respondents having had mild experiences of physical and sexual violence was very small (1 and $2 \%$, respectively), whereas this was $12 \%$ for psychological violence. Comparing sexes, we found significant differences for severe physical violence (more male respondents) and for moderate and severe sexual violence (more female respondents). Current age did not yield any significant differences with respect to physical and sexual IV, implying that in all age bands the self-reported prevalence rates for mild, moderate and severe IV were similar. Lastly, the younger respondents reported more incidents of mild and moderate psychological violence, but the prevalence of severe psychological violence was comparable for all age groups.

Insert Table 6 about here 


\section{Discussion}

The present retrospective study was designed to assess the prevalence of IV against children in sport in a representative sample of Flemish and Dutch adults (up to 50 years of age). Our online survey showed the overall prevalence of self-reported psychological violence to be $38 \%$. Although the prevalence rates for physical and sexual violence (11\% and $14 \%$, respectively) are lower, together the results we obtained underline the existence of IV in youth sport.

Comparing our data with those Alexander et al. recorded in the United Kingdom, we see remarkably higher prevalence estimates of psychological violence or emotional harm (75\%) and physical violence (24\%) in their study (2011), with sexual harassment also being significantly more frequently reported than was the case in our study. The low response rate in the Alexander et al. study may have caused a bias in favor of respondents with IV experiences, accounting for the high percentages. Comparison with other studies on (sexual) harassment and abuse in youth sport is difficult because of the differences in definitions, focus (i.e., coach behaviors towards athletes only while we included peer-to-peer violence), and question sets.

\section{Differences in national IV prevalence rates}

Whilst we found no differences in the prevalence of psychological violence between Flemish and Dutch respondents, the prevalence rates for physical and sexual violence were significantly higher in the Flemish respondents. Given that most of the respondents were active athletes before the 1990s, we cannot explain the prevalence difference by reference to the differences in the stages of the prevention strategies in the two countries (gradual implementation in the Netherlands from the 1990s versus the very recent such initiatives in Flanders). Moreover, we found no significant differences in IV prevalence between Flanders and the Netherlands in the youngest age group (active in youth sport in the 2000s). Interestingly, earlier studies also revealed higher prevalence 
estimates of bullying in school-aged children in Belgium versus the Netherlands (Currie et al., 2012) as well as higher rates for (attempted) suicide and self-harming behavior in children (Portzky, De Wilde, \& van Heeringen, 2008). Offering explanations for these important differences falls outside the scope of our article, but we can venture that it is very likely that cultural differences are of influence.

\section{Gender-related differences in IV prevalence}

Our results on gender differences support the findings of Alexander et al. (2011) who, like us, found no significant differences for psychological violence but did find higher rates of malereported physical violence and female-reported sexual violence, which is in line with other studies on childhood sexual abuse. However, as sexual violence is a gendered process (Hlavka, 2014), there is a taboo for male victims to report such events, which decreases the likelihood of them disclosing sexual victimization especially in gendered settings such as sports (Hartill, 2005; Vertommen, Schipper-van Veldhoven, Hartill, \& Van Den Eede, 2013). As a result, underreporting might be more pronounced in male respondents.

\section{Age-dependent differences in IV prevalence}

Experiences of physical and sexual violence did not appear to significantly differ based on the decade in which the respondents participated in youth sport (see Table 5). IV is therefore not a new problem and has been faced by children for many years. However, respondents who were younger in 2014 reported more incidents of childhood psychological violence than their older peers did. Indeed, in their study on unwanted behavior in Dutch sport (Tiessen-Raaphorst et al., 2008) showed that their participants felt that society is becoming increasingly (verbally) aggressive and less tolerant, and that these tendencies are mirrored in sport. Younger respondents may then perceive and report more aggressive behavior. The increase in self-reported psychological violence in recent 
years could also reflect an increased intensity in youth sports with the general development of greater competitiveness and commercialization (Collins, 2013; Lavalette, 2013). Given that the prevalence of psychological IV showed a gradual decrease with age, we offer that memories of (milder) incidents of psychological violence fade more quickly, which seems plausible since the rates of physical and sexual IV and reports of severe IV were consistent across age bands. The evidence suggesting that physical and sexual abuse of children outside sports decreased between 1993 and the mid-2000s in the US and the United Kingdom (Finkelhor \& Jones, 2012) was not confirmed by our study.

\section{Risk factors for IV in sport}

An important finding of this study is that minority groups (i.e., ethnic minority and LGB respondents and those having participated in disabled sport) had all experienced more IV. Remarkably, bisexual respondents reported even more incidents than their gay and heterosexual peers, with ORs as high as 3 for physical and sexual violence. In accordance, childhood IV studies outside sport have shown that LGB adults report higher rates than heterosexuals, with an average OR of 4 (Balsam et al., 2005; Friedman et al., 2011). Secondly, our study also confirms the findings that physical and mental disabilities are associated with an increased risk of childhood sexual and physical violence (Jones et al., 2012; Putnam, 2003). Thirdly, although the difference was small, the respondents with an ethnic background different from the Dutch and Flemish populations also showed increased exposure to physical and sexual violence (but not psychological violence). Ethnicity is consistently found to be associated with each type of IV, but not in a uniform pattern, and in most cases the association is weakened after adjustment for sociodemographic characteristics (Hussey et al., 2006). Still, minority groups that already face more challenges to engage in sports indeed face higher risks of experiencing psychological, physical, and sexual violence. 
In conformity with other studies on sexual and emotional abuse in sport, we found an increased level of self-reported IV among former international youth athletes (Gervis \& Dunn, 2004; Leahy et al., 2002; Stirling \& Kerr, 2007). Being an elite (young) athlete, investing an immense amount of time, money, energy in sport, has systematically shown to significantly increase the risk of exposure to IV in sport. The low values of the pseudo $\mathrm{R}$ squared in all 3 models indicate that there are many other unknown factors having an influence on IV in sport.

\section{Limitations}

Surveying a sensitive issue like IV against children requires a thoughtful and carefully justified approach. Findings from the literature generally suggest that estimates of prevalence rates for difficult topics are best based on self-administered interviews (Aquilino, 1994; Catania, Dermott, \& Pollack, 1986). Nonetheless, instead of interviewing children, we chose to use a faster retrospective design. This approach, which is less invasive and precludes the need for parental consent, was also adopted in the national prevalence studies in the United Kingdom (Cawson, 2000; Radford et al., 2011).

Using an online panel for scientific purposes can be methodologically problematic. First, using the Internet leads to an underrepresentation of those groups that have no or difficult access to this. Also, the researcher can never check whether the person to whom it was sent completed the questionnaire. Another constraint of this format was that the fieldwork was terminated as soon as the target number of participants was reached, preventing the exact response rate from being determined. Our sample can hence be best described as a convenience sample of respondents who have chosen to be panel members and are thus willing and able to fill out a questionnaire relatively rapidly. Taking these restrictions into account, we found no evidence that falsifies the claim that our 
samples are representative of the respective target populations. Even so, as there are no detailed demographic characteristics available of all children participating in organized sport since the 1970s in Flanders and the Netherlands, we are unable to demonstrate the representativeness of our samples. Despite that, and being the first of its kind in the Netherlands and Belgium, our study has a sufficiently large sample taken from a comparatively general population, with a balanced gender ratio and a wide variety in ages, education, sexual preference, ethnicity, marital status, and number and level of sports played.

Finally, the validity of retrospective reports of adverse childhood experiences is frequently debated in the literature (e.g., Hardt \& Rutter, 2004) as such reports tend to involve a substantial number of false negatives and measurement errors, whereas false positive reports are thought to be less probable. Given the latter assumption, we feel that our prevalence estimates are likely to underestimate the prevalence of IV in sport.

\section{Future research and recommendations}

Our survey produced an enormous volume of data, which is why additional analyses on the alleged perpetrators, sport disciplines, circumstances and impact of the reported IV will be undertaken and reported in future articles.

Worldwide, organized sport is an important leisure activity for millions of children where, sadly, societal problems also become manifest. The prevalence rates we obtained are in line with the available data on IV outside sport and justify all policy efforts to prevent any form of IV against children in sport. Compared to the family setting, sport settings are probably more susceptible to social interventions aimed at preventing childhood (sexual) maltreatment because of sports' voluntary structures and the many more possibilities to intervene (Vertommen, ToftegaardStoeckel, Vandevivere, Van Den Eede, \& De Martelaer, 2014). 
The recent introduction of international safeguarding standards in sport to help sport organizations endorse child protection procedures is a welcome initiative (Mountjoy, Rhind, Tiivas, \& Leglise, 2015). Still, to foster and support (inter-)national attempts to protect children in organized sport across the world, we need to recurrently perform prevalence surveys using standardized and internationally validated instruments in as many countries as possible.

Our study demonstrates that violence against children truly is a problem in Dutch and Flemish sport, warranting attention, as it does elsewhere. The notion that psychological, physical and sexual violence affects at least one child in every sports team, is unacceptable, while the elevated prevalence in young disabled, LGB, ethnic minority, and elite athletes urges us to devote careful consideration to these groups in future research, policies, and, above all, practice. 


\section{References}

Alexander, K., Stafford, A., \& Lewis, R. (2011). The experiences of children participating in organised sport in the UK. Edinburgh: Dunedin Academic Press.

Aquilino, W. S. (1994). Interview mode effects in surveys of drug and alcohol use. Public Opinion Quarterly, 58, 210-240.

Baar, P., \& Wubbels, T. (2013). Peer Aggression and Victimization : Dutch Sports Coaches' Views and Practices. The Sport Psychologisy, 27, 380-389.

Balsam, K. F., Rothblum, E. D., \& Beauchaine, T. P. (2005). Victimization over the life span: a comparison of lesbian, gay, bisexual, and heterosexual siblings. Journal of Consulting and Clinical Psychology, 73(3), 477-487. doi:10.1037/0022-006X.73.3.477

Bernstein, D. P., Fink, L., Handelsman, L., \& Foote, J. (1994). Initial reliability and validity of a new retrospective measure of child abuse and neglect. American Journal of Psychiatry, 151(8), $1132-1136$.

Brackenridge, C. H. (2010). Violence and abuse prevention in sport. In K. Kaufman (Ed.), The Prevention of Sexual Violence: A Practitioners'Sourcebook (pp. 401-413). Holyoke, M.A.: NEARI Press.

Catania, J. A., Dermott, L. J., \& Pollack, L. M. (1986). Questionnaire response bias and face-to-face interview sample: Bias in sexuality research. The Journal of Sex Research, 22(1), 52-72.

Cawson, P. (2000). Child Maltreatment in the United Kingdom: a Study of the Prevalence of Abuse and Neglect.

Cense, M., \& Brackenridge, C. H. (2001). Temporal and developmental risk factors for sexual harassment and abuse in sport. European Physical Education Review, 7(1), 61-79.

Collard, D., \& Hoekman, R. (2012). Sportdeelname in Nederland: 2006 - 2011. Utrecht: Mulier Instituut.

Collard, D., \& Pulles, I. (2014). Sportdeelname 2013. Utrecht: Mulier Instituut.

Collins, T. (2013). Sport in Capitalist Society: A short history. London: Routledge.

Committee on the Rights of the Child. (2011). General comment No.13 The right of the child to freedom from all forms of violence. Geneva. Retrieved from http://www2.ohchr.org/english/bodies/crc/docs/CRC.C.GC.13_en.pdf

Currie, C., Zanotti, C., Morgan, A., Currie, D., de Looze, M., Roberts, C., ... Barnekow, V. (2012). Social determinants of health and well-being among young people. Health Behaviour in School-aged Children (HBSC) study: International report from the 2009/2010 survey.

David, P. (2004). Human Rights in Youth Sport: A critical review of children's rights in competitive sport. London: Routledge.

DiLillo, D., DeGue, S., Kras, A., Di Loreto-Colgan, A. R., \& Nash, C. (2006). Participant responses to retrospective surveys of child maltreatment: does mode of assessment matter? Violence Vict, 21(4), 410-424. Retrieved from http://www.ncbi.nlm.nih.gov/pubmed/16897910

Fasting, K., Brackenridge, C., \& Sundgot-Borgen, J. (2003). Experiences of Sexual Harassment and Abuse Among Norwegian Elite Female Athletes and Nonathletes. Research Quarterly for Exercise and Sport, 74(1), 84-97.

Fasting, K., Chroni, S., Hervik, S. E., \& Knorre, N. (2011). Sexual harassment in sport toward females in three European countries. International Review for the Sociology of Sport, 46(1), 76-89. doi:10.1177/1012690210376295

Felitti, V. J., Anda, R. F., Nordenberg, D., Williamson, D. F., Spitz, A. M., Edwards, V., ... Marks, J. S. (1998). Relationship of childhood abuse and household dysfunction to many of the leading causes of death in adults. American Journal of Preventive Medicine, 14(4), 245-258. 
Finkelhor, D., \& Jones, L. (2012). Trends in child maltreatment. The Lancet, 379(9831), 2048-9; author reply 2049. doi:10.1016/S0140-6736(12)60888-5

Friedman, M. S., Marshal, M. P., Guadamuz, T. E., Wei, C., Wong, C. F., Saewyc, E. M., \& Stall, R. (2011). A meta-analysis of disparities in childhood sexual abuse, parental physical abuse, and peer victimization among sexual minority and sexual nonminority individuals. American Journal of Public Health, 101(8), 1481-1494. doi:10.2105/AJPH.2009.190009

Gervis, M., \& Dunn, N. (2004). The emotional abuse of elite child athletes by their coaches. Child Abuse Review, 13, 215-223. doi:10.1002/car.843

Hamby, S. L., \& Koss, M. P. (2003). Shades of gray: A qualitative study of terms used in the measurement of sexual victimization. Psychology of Women Quarterly, 27(3), 243-255. doi:10.1111/1471-6402.00104

Hardt, J., \& Rutter, M. (2004). Validity of adult retrospective reports of adverse childhood experiences: review of the evidence. Journal of Child Psychology and Psychiatry, 45(2), 260 273.

Hartill, M. (2005). Sport and the sexually abused male child. Sport Education and Society, 10(3), 287-304. doi:10.1080/13573320500254869

Hintze, J. (2011). PASS 11. Utah, USA: NCSS.

Hlavka, H. R. (2014). Normalizing Sexual Violence: Young Women Account for Harassment and Abuse. Gender \& Society, 28(3), 337-358. doi:10.1177/0891243214526468

Hussey, J. M., Chang, J. J., \& Kotch, J. B. (2006). Child maltreatment in the United States: prevalence, risk factors, and adolescent health consequences. Pediatrics, 118(3), 933-942. doi:10.1542/peds.2005-2452

Jones, L., Bellis, M. A., Wood, S., Hughes, K., McCoy, E., Eckley, L., ... Officer, A. (2012). Prevalence and risk of violence against children with disabilities: a systematic review and meta-analysis of observational studies. Lancet, 380(9845), 899-907. doi:10.1016/S01406736(12)60692-8

Kirby, S., Greaves, L., \& Hankivsky, O. (2000). The Dome of Silence: Sexual Harassment and Abuse in Sport. Halifax: Fernwood Publishing.

Krug, E. G., Mercy, J. A., Dahlberg, L. L., \& Zwi, A. B. (2002). The world report on violence and health. The Lancet, 360(9339), 1083-1088.

Lavalette, M. (2013). Capitalism and Sport: Politics, protest, people and play. (M. Lavalette, Ed.). London: Bookmarks.

Leahy, T., Pretty, G., \& Tenenbaum, G. (2002). Prevalence of sexual abuse in organised competitive sport in Australia. Journal of Sexual Aggression, 8(2), 16-36.

Mountjoy, M., Rhind, D., Tiivas, A., \& Leglise, M. (2015). Safeguarding the child athlete in sport. British Journal of Sports Medicine.

Portzky, G., De Wilde, E.-J., \& van Heeringen, K. (2008). Deliberate self-harm in young people: differences in prevalence and risk factors between the Netherlands and Belgium. European Child \& Adolescent Psychiatry, 17, 179-186. doi:10.1007/s00787-007-0652-x

Putnam, F. W. (2003). Ten-year research update review: Child sexual abuse. Journal of the American Academy of Child Adolesc Psychiatry, 42(3), 269-278. doi:10.1097/01.chi.0000037029.04952.72

Radford, L., Corral, S., Bradley, C., Fisher, H., Bassett, C., Howat, N., Collishaw, S. (2011). Child abuse and neglect in the UK today. London: National Society for the Prevention of Cruelty to Children.

Romijn, D., van Kalmthout, J., Breedveld, K., \& Lucassen, J. (2013). VSK-monitor 2013. Voortgangsrapportage Actieplan "Naar een veiliger sportklimaat." Utrecht. 
Rosenbaum, A., \& Langhinrichsen-Rohling, J. (2006). Meta-research on violence and victims: the impact of data collection methods on findings and participants. Violence and Victims, 21(4), 404-409. Retrieved from http://www.ncbi.nlm.nih.gov/pubmed/16897909

Rosenbaum, A., Rabenhorst, M. M., Reddy, M. K., Fleming, M. T., \& Howells, N. L. (2006). A comparison of methods for collecting self-report data on sensitive topics. Violence and Victims, 21(4), 461-471. Retrieved from http://www.ncbi.nlm.nih.gov/pubmed/16897913

Schipper - van Veldhoven, N., Vertommen, T., \& Vloet, L. (2014). Sexul Intimidation in Sport: the Netherlands. In M. Lang \& M. Hartill (Eds.), Safeguarding, Child Protection and Abuse in Sport: International Perspectives in Research, Policy and Practice. London: Routledge.

Schipper-van Veldhoven, N. H. (2012). Sports in a pedagogical perspective. In S. Harvey \& R. Light (Eds.), Ethics in Youth Sport: Policy and pedagogical applications (pp. 122-135). London: Routledge.

Stafford, A., \& Fry, D. (2013). Playing through Pain: Children and Young People's Experiences of Physical Aggression and Violence in Sport. Child Abuse Review, 22(April), 287-299. doi:10.1002/car

Stirling, A. E., Bridges, E. J., Cruz, E. L., \& Mountjoy, M. L. (2011). Canadian Academy of Sport and Exercise Medicine position paper: abuse, harassment, and bullying in sport. Clinical Journal of Sports Medicine, 21(5), 385-391. doi:10.1097/JSM.0b013e31820f9248

Stirling, A. E., \& Kerr, G. A. (2007). Elite female swimmers' experiences of emotional abuse across time. Journal of Emotional Abuse, 7(4), 89-113.

Stirling, A. E., \& Kerr, G. A. (2012). The perceived effects of elite athletes' experiences of emotional abuse in the coach-athlete relationship. International Journal of Sport and Exercise Psychology.

Tiessen-Raaphorst, A., \& Breedveld, K. (2007). Een gele kaart voor de sport.

Tiessen-Raaphorst, A., Lucassen, J., van den Dool, R., \& van Kalmthout, J. (2008). Weinig over de schreef. Een onderzoek naar onwenselijk gedrag in de breedtesport.

United Nations. Convention on the Rights of the Child (1989). Switserland. Retrieved from http://www.ohchr.org/en/professionalinterest/pages/crc.aspx

United Nations. (2006). Report on Violence against Children (Vol. 49105). Retrieved from http://eric.ed.gov/?id=ED459272

Vandermeerschen, H., Vos, S., \& Scheerder, J. (2014). Towards level playing fields? A time trend analysis of young people's participation in club-organised sports. International Review for the Sociology of Sport. doi:1012690214532450

Vertommen, T., Schipper-van Veldhoven, N. H., Hartill, M. J., \& Van Den Eede, F. (2013). Sexual harassment and abuse in sport: The NOC*NSF helpline. International Review for the Sociology of Sport. doi:10.1177/1012690213498079

Vertommen, T., Stoeckel, J. T., Vandevivere, L., Van Den Eede, F., \& De Martelaer, K. (2014). A green flag for the Flag System? Towards a child protection policy in Flemish sport. International Journal of Sport Policy and Politics, 1-17. doi:10.1080/19406940.2014.947305

Vertommen, T., Tolleneer, J., Maebe, G., \& De Martelaer, K. (2014). Preventing child maltreatment and transgressive behaviour in Flemish sport. In Safeguarding, Child Protection and Abuse in Sport: International Perspectives in Research, Policy and Practice (pp. 31-39). London: Routledge. 
Table 1

Response classification based on expert-rated event severity and respondent-rated event frequency

Frequency

Once A few times $\quad$ Regularly, often

Mild Mild

Moderate

Event severity score 1

(low)

Event severity score 2

(medium)

Event severity score 3

(high) e.g., you were negatively criticized about e.g., your privacy was invaded (someone was your performance standing too close to you, etc.)

\section{Mild}

e.g., you were being touched during training in a way that made you uneasy

\section{Severe}

e.g., someone touched you sexually against your will
Moderate

e.g., you were put down, embarrassed or humiliated

\section{Severe}

e.g., you were hit with an object (e.g. shoe, racket, hockey stick) e.g., you were shouted or cursed at

\section{Severe}

e.g., you were threatened with being thrown out (of the team, club, gym, etc.)

\section{Severe}

e.g., you were grabbed by the throat / choked, You were forced to have sex with penetration 
Table 2

Sociodemographic and sports participation characteristics for all respondents

\begin{tabular}{|c|c|c|c|c|c|c|}
\hline & & \multirow[t]{2}{*}{$\begin{array}{l}\text { Total sample } \\
(\mathrm{N}=4043)\end{array}$} & \multicolumn{2}{|c|}{$\begin{array}{l}\text { Netherlands } \\
(\mathrm{N}=1999)\end{array}$} & \multicolumn{2}{|c|}{$\begin{array}{l}\text { Flanders, Belgium } \\
\qquad(\mathrm{N}=2044)\end{array}$} \\
\hline & & & Female & Male & Female & Male \\
\hline & & $N(\%)$ & $N(\%)$ & $N(\%)$ & $\mathrm{N}(\%)$ & $N(\%)$ \\
\hline \multirow[t]{5}{*}{ Age } & $18-24$ years & 718 (17.8) & $179(18.2)$ & $183(18)$ & $254(20.7)$ & $102(12.5)$ \\
\hline & $25-34$ years & $1,214(30.0)$ & $298(30.3)$ & $265(26.1)$ & $425(34.6)$ & $226(27.7)$ \\
\hline & $35-44$ years & $1,264(31.3)$ & $300(30.5)$ & $347(34.2)$ & $344(28)$ & $273(33.5)$ \\
\hline & $45-50$ years & 847 (20.9) & $207(21)$ & $220(21.7)$ & $205(16.7)$ & $215(26.3)$ \\
\hline & Total & $4,043(100.0)$ & $9,84(100.0)$ & $1,015(100.0)$ & $1,228(100.0)$ & $816(100.0)$ \\
\hline \multirow[t]{4}{*}{ Education } & Low & 651 (16.1) & $178(18.1)$ & $182(17.9)$ & $154(12.6)$ & 137 (16.9) \\
\hline & Moderate & $1,706(42.2)$ & 471 (47.9) & $478(47.1)$ & $430(35.2)$ & $327(40.4)$ \\
\hline & High & $1,674(41.4)$ & $335(34)$ & 355 (35) & $638(52.2)$ & $346(42.7)$ \\
\hline & Total & 4,031 (99.7) & $984(100.0)$ & $1,015(100.0)$ & $1,222(100.0)$ & $810(100.0)$ \\
\hline \multirow[t]{4}{*}{ Sexual preference } & Heterosexual & 3,672 (90.8) & 914 (94.9) & $942(93.5)$ & 1090 (90.5) & $726(90.1)$ \\
\hline & Gay & $166(4.1)$ & $21(2.2)$ & $42(4.2)$ & $58(4.8)$ & $45(5.6)$ \\
\hline & Bisexual & $143(3.5)$ & $28(2.9)$ & $23(2.3)$ & $57(4.7)$ & $35(4.3)$ \\
\hline & Total & $3,981(98.5)$ & $963(100.0)$ & $1,007(100.0)$ & $1,205(100.0)$ & $806(100.0)$ \\
\hline \multirow[t]{4}{*}{ Ethnicity } & Dutch/Belgian origin & 3693 (91.3) & $891(90.8)$ & 927 (91.6) & $1122(92)$ & 753 (92.4) \\
\hline & Ethnic minority (self, father & & & & & \\
\hline & and/or mother) & $335(8.3)$ & $90(9.2)$ & $85(8.4)$ & $98(8)$ & $62(7.6)$ \\
\hline & Total & $4,028(99.6)$ & $981(100.0)$ & $1,012(100.0)$ & $1,220(100.0)$ & $815(100.0)$ \\
\hline \multirow[t]{6}{*}{ Marital status } & Married & 1,513 (37.4) & $403(41.0)$ & $416(41.0)$ & $391(31.8)$ & $303(37.1)$ \\
\hline & $\begin{array}{l}\text { Cohabitant } \\
\text { In a relationship (non- }\end{array}$ & $938(23.2)$ & $219(22.3)$ & $203(20.0)$ & $321(26.1)$ & 195 (23.9) \\
\hline & cohabitant) & $494(12.2)$ & 112 (11.4) & $107(10.5)$ & $180(14.7)$ & 95 (11.6) \\
\hline & Divorced and single & $213(5.3)$ & $51(5.2)$ & $29(2.9)$ & $84(6.8)$ & $49(6)$ \\
\hline & Single (never married) & $752(18.6)$ & $171(17.4)$ & $224(22.1)$ & $202(16.4)$ & $155(19)$ \\
\hline & Widow(er) & $14(0.3)$ & $5(0.5)$ & $1(0.1)$ & $7(0.6)$ & $1(0.1)$ \\
\hline
\end{tabular}




\begin{tabular}{|c|c|c|c|c|c|c|}
\hline & Other & $89(2.2)$ & $15(1.5)$ & $32(3.2)$ & $34(2.8)$ & $8(1.0)$ \\
\hline & Prefer not to tell & $30(0.7)$ & $8(0.8)$ & $3(0.3)$ & $9(0.7)$ & $10(1.2)$ \\
\hline & Total & $4,043(100.0)$ & $984(100.0)$ & $1,015(100.0)$ & $1,228(100.0)$ & $816(100.0)$ \\
\hline \multirow{4}{*}{$\begin{array}{l}\text { Participation in sport } \\
\text { for disabled children }\end{array}$} & Yes, exclusively & $52(1.3)$ & $10(1.0)$ & $6(0.6)$ & $13(1.1)$ & $23(2.8)$ \\
\hline & Yes, but not exclusively & $133(3.3)$ & $22(2.2)$ & $29(2.9)$ & $33(2.7)$ & $49(6.0)$ \\
\hline & No & 3849 (95.2) & $952(96.7)$ & 977 (96.5) & $1180(96.2)$ & 740 (91.1) \\
\hline & Total & 4,034 (99.8) & $984(100.0)$ & $1,012(100.0)$ & $1,226(100.0)$ & $812(100.0)$ \\
\hline \multirow[t]{6}{*}{ Number of sports } & 1 sport & $1262(31.2)$ & $217(22.1)$ & $275(27.1)$ & $432(35.2)$ & 338 (41.4) \\
\hline & 2 sports & 1015 (25.1) & $248(25.2)$ & $296(29.2)$ & $279(22.7)$ & $192(23.5)$ \\
\hline & 3 sports & 757 (18.7) & $223(22.7)$ & 192 (18.9) & $230(18.7)$ & $112(13.7)$ \\
\hline & 4 sports & 499 (12.3) & 147 (14.9) & $136(13.4)$ & $144(11.7)$ & $72(8.8)$ \\
\hline & 5 sports & $510(12.6)$ & $149(15.1)$ & $116(11.4)$ & $143(11.6)$ & $102(12.5)$ \\
\hline & Total & $4,043(100.0)$ & $984(100.0)$ & $1,015(100.0)$ & $1,228(100.0)$ & $816(100.0)$ \\
\hline \multirow[t]{5}{*}{ Sport organization } & Sports club & 3898 (96.4) & $967(98.3)$ & 990 (97.5) & 1160 (94.5) & 781 (95.7) \\
\hline & Informal groups of & & & & & \\
\hline & triends/family & $1,399(34.6)$ & $\begin{array}{l}218(28.3) \\
249(25.3)\end{array}$ & $342(33.7)$ & $\begin{array}{l}407(33.1) \\
287(23.1)\end{array}$ & $\begin{array}{l}3 / 2(45.6) \\
282(246)\end{array}$ \\
\hline & $\begin{array}{l}\text { Alone, non-organized } \\
\text { Member of commercial sport }\end{array}$ & $1,108(27.4)$ & $249(25.3)$ & $290(28.6)$ & $287(23.4)$ & $282(34.6)$ \\
\hline & provider & $1,021(25.3)$ & $270(27.4)$ & $217(21.4)$ & $341(27.8)$ & $193(23.7)$ \\
\hline \multirow[t]{6}{*}{ Highest sport level } & Recreational & $1,239(30.6)$ & $285(29)$ & 173 (17) & 599 (48.8) & $182(22.4)$ \\
\hline & Competitive, local level & $1,023(25.3)$ & 311 (31.6) & $281(27.7)$ & $254(20.7)$ & $177(21.7)$ \\
\hline & Competitive, regional level & $1,245(30.8)$ & $289(29.4)$ & $428(42.2)$ & $230(18.7)$ & $298(36.6)$ \\
\hline & Competitive, national level & $421(10.4)$ & $79(8.0)$ & $104(10.2)$ & $110(9.0)$ & $128(15.7)$ \\
\hline & Competitive, international level & $112(2.8)$ & 19 (1.9) & $29(2.9)$ & 35 (2.9) & 29 (3.6) \\
\hline & Total & 4,040 (99.9) & $983(100.0)$ & $1,015(100.0)$ & $1,228(100.0)$ & $814(100.0)$ \\
\hline
\end{tabular}


Table 3

Prevalence of childhood interpersonal violence (IV) in sport per type for the total study sample (low threshold measure, i.e. at least one experience)

\begin{tabular}{|c|c|c|c|c|c|}
\hline & $\begin{array}{c}\text { Psychological } \\
\text { Violence }\end{array}$ & $\begin{array}{l}\text { Physical } \\
\text { Violence }\end{array}$ & $\begin{array}{c}\text { Sexual } \\
\text { Violence }\end{array}$ & $\begin{array}{c}\text { At least one type } \\
\text { of IV }\end{array}$ & $\begin{array}{c}\text { All types } \\
\text { of IV }\end{array}$ \\
\hline $\mathrm{N}$ of respondents & 1,520 & 455 & 578 & 1,785 & 167 \\
\hline$\%$ & 37.6 & 11.3 & 14.3 & 44.2 & 4.1 \\
\hline Confidence Interval (99\%) & $35.7-39.6$ & $10.0-12.6$ & $12.9-15.8$ & $42.1-46.2$ & $3.4-5.0$ \\
\hline
\end{tabular}


Table 4

Reported prevalence of the three types of childhood interpersonal violence (IV) in sport per subgroup (low threshold measure, i.e. at least one experience)

\begin{tabular}{|c|c|c|c|c|}
\hline & & Psychological Violence & Physical Violence & Sexual Violence \\
\hline & & $N(\%)$ & $N(\%)$ & $N(\%)$ \\
\hline \multirow[t]{2}{*}{ Country } & the Netherlands & 735 (36.8) & $196(9.8)$ & 237 (11.9) \\
\hline & Flanders, Belgium & $785(38.5)$ & $259(12.7)$ & 341 (16.7) \\
\hline \multirow[t]{2}{*}{ Gender } & Female & $803(36.3)$ & $195(8.8)$ & $380(17.2)$ \\
\hline & Male & $717(39.2)$ & $260(14.2)$ & $198(10.8)$ \\
\hline \multirow[t]{4}{*}{ Age } & $18-24$ years & $332(46.4)$ & $93(13.0)$ & $123(17.2)$ \\
\hline & $25-34$ years & 505 (41.7) & $127(10.5)$ & 163 (13.4) \\
\hline & $35-44$ years & 431 (34.1) & $132(10.5)$ & $176(14.0)$ \\
\hline & $45-50$ years & $252(29.8)$ & $103(12.2)$ & $116(13.7)$ \\
\hline \multirow[t]{3}{*}{ Sexual preference } & Heterosexual & 1,355 (36.9) & $385(10.5)$ & $489(13.3)$ \\
\hline & Gay & 65 (39.4) & $21(12.7)$ & $34(20.6)$ \\
\hline & Bisexual & 73 (51.0) & $39(27.5)$ & $43(30.3)$ \\
\hline \multirow[t]{2}{*}{ Ethnicity } & Dutch/Belgian origin & $1,382(37.5)$ & $387(10.5)$ & 505 (13.7) \\
\hline & Ethnic minority (self, father and/or mother) & $131(39.2)$ & 64 (19.1) & $68(20.3)$ \\
\hline Participation in sport & No & $1,425(37.0)$ & $393(10.2)$ & $512(13.3)$ \\
\hline for disabled children & Yes & $91(49.7)$ & $60(32.4)$ & $62(33.5)$ \\
\hline \multirow[t]{5}{*}{ Highest sporting achievement } & Recreational level ( $N=1239)$ & $408(32.9)$ & $102(8.2)$ & $168(13.6)$ \\
\hline & Local level $(N=1023)$ & $396(38.8)$ & $108(10.6)$ & $141(13.8)$ \\
\hline & Regional level ( $\mathrm{N}=1245)$ & $503(40.4)$ & $156(12.5)$ & 173 (13.9) \\
\hline & National level $(\mathrm{N}=421)$ & $151(35.9)$ & $60(14.3)$ & $64(15.2)$ \\
\hline & International level ( $\mathrm{N}=112)$ & $61(55.0)$ & $29(25.0)$ & $32(28.6)$ \\
\hline
\end{tabular}


Table 5

Results for the simple and multiple logistic regressions per type of childhood sport-related interpersonal violence (IV) (low threshold measure, i.e. at least one experience)

\begin{tabular}{|c|c|c|c|c|c|c|c|}
\hline \multirow{2}{*}{$\begin{array}{l}\text { Psychological Violence } \\
\mathrm{R}^{2} \text { McFadden }=0.022 \text { (Multiple log reg) }\end{array}$} & & \multicolumn{3}{|c|}{ Simple logistic regression } & \multicolumn{3}{|c|}{ Multiple logistic regression } \\
\hline & & OR & $99 \% \mathrm{Cl}$ & $\mathrm{p}$ & OR & $99 \% \mathrm{Cl}$ & $p$ \\
\hline \multirow[t]{2}{*}{ Country } & the Netherlands ${ }^{\circ}$ & & & & & & \\
\hline & Flanders, Belgium & 1.074 & $0.908-1.270$ & 0.272 & 1.106 & $0.927-1.319$ & 0.141 \\
\hline \multirow[t]{2}{*}{ Gender } & Female $^{\circ}$ & 1.000 & & & & & \\
\hline & Male & 1.130 & $0.955-1.336$ & 0.061 & 1.145 & $0.957-1.370$ & 0.052 \\
\hline \multirow[t]{4}{*}{ Age } & $18-24$ years $^{\circ}$ & & & & & & \\
\hline & $25-34$ years & 0.826 & $0.647-1.055$ & 0.044 & 0.808 & $0.630-1.037$ & 0.028 \\
\hline & $35-44$ years & 0.598 & $0.468-0.766$ & 0.000 & 0.576 & $0.447-0.741$ & 0.000 \\
\hline & $45-50$ years & 0.490 & $0.373-0.644$ & 0.000 & 0.477 & $0.361-0.632$ & 0.000 \\
\hline \multirow[t]{3}{*}{ Sexual preference } & Heterosexual $^{\circ}$ & & & & & & \\
\hline & Gay & 1.110 & $0.730-1.689$ & 0.552 & 1.051 & $0.683-1.619$ & 0.765 \\
\hline & Bisexual & 1.781 & $1.147-2.765$ & 0.001 & 1.709 & $1.087-2.685$ & 0.002 \\
\hline \multirow[t]{2}{*}{ Ethnicity } & Dutch/Belgian origin $^{\circ}$ & & & & & & \\
\hline & Ethnic minority (self, father and/or mother) & 0.928 & $0.686-1.255$ & 0.523 & 0.995 & $0.727-1.363$ & 0.969 \\
\hline \multirow[t]{2}{*}{$\begin{array}{l}\text { Participation in sport for disabled } \\
\text { children }\end{array}$} & $\mathrm{No}^{\circ}$ & & & & & & \\
\hline & Yes & 1.681 & $1.138-2.484$ & 0.001 & 1.314 & $0.869-1.988$ & 0.089 \\
\hline \multirow[t]{5}{*}{ Sport level } & Recreational level $(\mathrm{N}=1239)^{\circ}$ & & & & & & \\
\hline & Local level ( $N=1023)$ & 1.290 & $1.028-1.620$ & 0.004 & 1.047 & $1.047-1.681$ & 0.002 \\
\hline & Regional level $(\mathrm{N}=1245)$ & 1.383 & $1.115-1.715$ & 0.000 & 1.100 & $1.100-1.739$ & 0.000 \\
\hline & National level $(\mathrm{N}=421)$ & 1.139 & $0.840-1.545$ & 0.271 & 1.141 & $0.833-1.564$ & 0.280 \\
\hline & International level $(\mathrm{N}=112)$ & 2.485 & $1.484-4.161$ & 0.000 & 2.318 & $1.366-3.934$ & 0.000 \\
\hline \multicolumn{2}{|l|}{ Physical Violence } & \multicolumn{3}{|c|}{ Simple logistic regression } & \multicolumn{3}{|c|}{ Multiple logistic regression } \\
\hline $\mathrm{R}^{2}$ McFadden $=0.058$ (Multiple log reg) & & OR & $99 \% \mathrm{Cl}$ & $\mathrm{p}$ & OR & $99 \% \mathrm{Cl}$ & $\mathrm{p}$ \\
\hline \multirow[t]{2}{*}{ Country } & the Netherlands* & & & & & & \\
\hline & Flanders, Belgium & 1.336 & $1.031-1.730$ & 0.004 & 1.387 & $1.053-1.828$ & 0.002 \\
\hline Gender & Female $^{\circ}$ & & & & & & \\
\hline
\end{tabular}




\begin{tabular}{|c|c|c|c|c|c|c|c|}
\hline & Male & 1.711 & $1.321-2.217$ & 0.000 & 1.614 & $1.219-2.136$ & 0.000 \\
\hline \multirow[t]{4}{*}{ Age } & $18-24$ years $^{\circ}$ & & & & & & \\
\hline & $25-34$ years & 0.784 & $0.539-1.140$ & 0.094 & 0.753 & $0.509-1.118$ & 0.064 \\
\hline & $35-44$ years & 0.784 & $0.541-1.137$ & 0.091 & 0.779 & $0.527-1.153$ & 0.101 \\
\hline & $45-50$ years & 0.929 & $0.626-1.378$ & 0.630 & 1.036 & $0.686-1.565$ & 0.823 \\
\hline \multirow[t]{3}{*}{ Sexual preference } & Heterosexual $^{\circ}$ & & & & & & \\
\hline & Gay & 1.236 & $0.667-2.291$ & 0.377 & 1.049 & $0.548-2.006$ & 0.851 \\
\hline & Bisexual & 3.231 & $1.952-5.347$ & 0.000 & 2.593 & $1.506-4.462$ & 0.000 \\
\hline \multirow[t]{2}{*}{ Ethnicity } & Dutch/Belgian origin $^{\circ}$ & & & & & & \\
\hline & Ethnic minority (self, father and/or mother) & 2.016 & $1.373-2.959$ & 0.000 & 2.000 & $1.333-3.002$ & 0.000 \\
\hline \multirow[t]{2}{*}{$\begin{array}{l}\text { Participation in sport for disabled } \\
\text { children }\end{array}$} & $\mathrm{No}^{\circ}$ & & & & & & \\
\hline & Yes & 4.217 & $2.751-6.465$ & 0.000 & 3.225 & $2.019-5.152$ & 0.000 \\
\hline \multirow[t]{5}{*}{ Sport level } & Recreational level $(\mathrm{N}=1239)^{\circ}$ & & & & & & \\
\hline & Local level ( $N=1023$ ) & 1.316 & $0.906-1.912$ & 0.058 & 1.260 & $0.850-1.869$ & 0.130 \\
\hline & Regional level ( $N=1245)$ & 1.595 & $1.129-2.254$ & 0.001 & 1.437 & $0.992-2.083$ & 0.012 \\
\hline & National level ( $N=421)$ & 1.856 & $1.187-2.903$ & 0.000 & 1.642 & $1.028-2.621$ & 0.006 \\
\hline & International level $(\mathrm{N}=112)$ & 3.891 & $2.101-7.206$ & 0.000 & 3.175 & $1.643-6.136$ & 0.000 \\
\hline \multicolumn{2}{|l|}{ Sexual Violence } & \multicolumn{3}{|c|}{ Simple logistic regression } & \multicolumn{3}{|c|}{ Multiple logistic regression } \\
\hline $\mathrm{R}^{2}$ McFadden $=0.046$ (Multiple log reg) & & OR & $99 \% \mathrm{Cl}$ & $\mathrm{p}$ & OR & $99 \% \mathrm{Cl}$ & $\mathrm{p}$ \\
\hline \multirow[t]{2}{*}{ Country } & the Netherlands ${ }^{\circ}$ & & & & & & \\
\hline & Flanders, Belgium & 1.490 & $1.179-1.885$ & 0.000 & 1.382 & $1.007-1.773$ & 0.001 \\
\hline \multirow[t]{2}{*}{ Gender } & Female $^{\circ}$ & & & & & & \\
\hline & Male & 0.585 & $0.459-0.746$ & 0.000 & 0.451 & $0.340-0.600$ & 0.000 \\
\hline \multirow[t]{4}{*}{ Age } & $18-24$ years $^{\circ}$ & & & & & & \\
\hline & $25-34$ years & 0.749 & $0.536-1.047$ & 0.026 & 0.724 & $0.512-1.024$ & 0.017 \\
\hline & $35-44$ years & 0.783 & $0.563-1.090$ & 0.057 & 0.823 & $0.583-1.161$ & 0.145 \\
\hline & $45-50$ years & 0.766 & $0.533-1.101$ & 0.059 & 0.876 & $0.600-1.279$ & 0.367 \\
\hline \multirow[t]{3}{*}{ Sexual preference } & Heterosexual & & & & & & \\
\hline & Gay & 1.688 & $1.013-2.815$ & 0.008 & 0.941 & $0.426-2.075$ & 0.842 \\
\hline & Bisexual & 2.825 & $1.736-4.597$ & 0.000 & 1.287 & $0.640-2.586$ & 0.352 \\
\hline
\end{tabular}


Dutch/Belgian origin

Ethnic minority (self, father and/or mother)

$\mathrm{No}^{\circ}$

Yes

Sport level

Recreational level $(\mathrm{N}=1239)^{\circ}$

Local level $(\mathrm{N}=1023)$

Regional level $(\mathrm{N}=1245)$

National level $(\mathrm{N}=421)$

International level ( $\mathrm{N}=112)$

Gender*Sexual preference

Male*Gay

Male*Bisexual
1.606

$1.108-2.327$

0.001

1.535

$1.037-2.271$

0.005

\begin{tabular}{llllll}
3.281 & $2.157-4.991$ & 0.000 & 2.904 & $1.838-4.588$ & 0.000 \\
& & & & & \\
1.017 & $0.741-1.397$ & 0.888 & 1.218 & $0.872-1.703$ & 0.129 \\
1.026 & $0.780-1.385$ & 0.826 & 1.370 & $0.990-1.896$ & 0.013 \\
1.140 & $0.756-1.717$ & 0.411 & 1.443 & $0.939-2.218$ & 0.028 \\
2.543 & $1.424-4.540$ & 0.000 & 3.074 & $1.669-5.663$ & 0.000 \\
& & & 3.180 & $1.093-9.246$ & 0.005 \\
& & & 3.844 & $1.368-10.796$ & 0.001 \\
\hline
\end{tabular}

${ }^{\circ}=$ Reference categor 


\section{Table 6}

Expert-rated severity of the sport-related childhood interpersonal violence (IV) per gender and current age group

\begin{tabular}{|c|c|c|c|c|c|c|c|c|c|c|}
\hline & & \multirow[t]{2}{*}{ Total } & \multicolumn{3}{|c|}{ Gender } & \multicolumn{5}{|c|}{ Current Age } \\
\hline & & & Female & Male & & $18-24$ years & $25-34$ years & $35-44$ years & $45-50$ years & \\
\hline & & $(\mathrm{N}=4043)$ & $(\mathrm{N}=2210)$ & $(\mathrm{N}=1999)$ & $p$ & $(\mathrm{~N}=717)$ & $(\mathrm{N}=1214)$ & $(\mathrm{N}=1263)$ & $(\mathrm{N}=847)$ & $n$ \\
\hline & & $N(\%)$ & N (\%) & $N(\%)$ & & N (\%) & $N(\%)$ & N (\%) & N (\%) & r \\
\hline \multirow{4}{*}{$\begin{array}{l}\text { Psychological } \\
\text { Violence }\end{array}$} & No & $2,519(62.3)$ & $1,407(63.7)$ & $1,112(60.7)$ & 0.061 & 384 (53.6) & 707 (58.2) & $833(66.0)$ & $595(70.2)$ & 0.000 \\
\hline & Mild & 469 (11.6) & $242(11.0)$ & $227(12.4)$ & 0.153 & $120(16.7)$ & $161(13.3)$ & $132(10.5)$ & $56(6.6)$ & 0.000 \\
\hline & Moderate & $685(17.0)$ & 347 (15.7) & 338 (18.5) & 0.020 & $146(20.4)$ & 229 (18.9) & $186(14.7)$ & $124(14.6)$ & 0.001 \\
\hline & Severe & $368(9.1)$ & 214 (9.7) & $154(8.4)$ & 0.162 & $67(9.3)$ & $117(9.6)$ & 112 (8.9) & $72(8.5)$ & 0.819 \\
\hline \multirow{4}{*}{$\begin{array}{l}\text { Physical } \\
\text { Violence }\end{array}$} & No & 3,568 (88.7) & 2,016 (91.2) & $1,570(85.8)$ & 0.000 & $624(87.0)$ & $1,087(89.5)$ & $1,131(89.5)$ & $744(87.8)$ & 0.224 \\
\hline & Mild & $44(1.1)$ & $29(1.3)$ & $15(0.8)$ & 0.134 & $10(1.4)$ & $14(1.2)$ & $8(0.6)$ & $12(1.4)$ & 0.267 \\
\hline & Moderate & 85 (1.2) & $50(2.3)$ & $35(1.9)$ & 0.442 & $18(2.5)$ & $23(1.9)$ & $29(2.3)$ & $15(1.8)$ & 0.678 \\
\hline & Severe & $326(8.1)$ & $116(5.2)$ & $210(11.5)$ & 0.000 & $65(9.1)$ & $90(7.4)$ & $95(7.5)$ & $76(9.0)$ & 0.376 \\
\hline \multirow{4}{*}{$\begin{array}{l}\text { Sexual } \\
\text { Violence }\end{array}$} & No & $3,460(85.6)$ & $1,829(82.8)$ & 1,631 (89.1) & 0.000 & $593(82.7)$ & 1,051 (86.6) & 1,085 (85.9) & 731 (86.3) & 0.117 \\
\hline & Mild & $63(1.6)$ & 42 (1.9) & 21 (1.1) & 0.055 & $19(2.6)$ & $15(1.2)$ & $17(1.3)$ & $12(1.4)$ & 0.076 \\
\hline & Moderate & $293(7.3)$ & $196(8.9)$ & $97(5.3)$ & 0.000 & $59(8.2)$ & $83(6.8)$ & $94(7.4)$ & $57(6.7)$ & 0.630 \\
\hline & Severe & $224(5.5)$ & $143(6.5)$ & $81(4.4)$ & 0.005 & 46 (6.4) & $64(5.3)$ & $67(5.3)$ & $47(5.5)$ & 0.717 \\
\hline
\end{tabular}


Figure 1 Proportions and correlations of the three types of IV (low threshold measure, i.e. at least one experience)

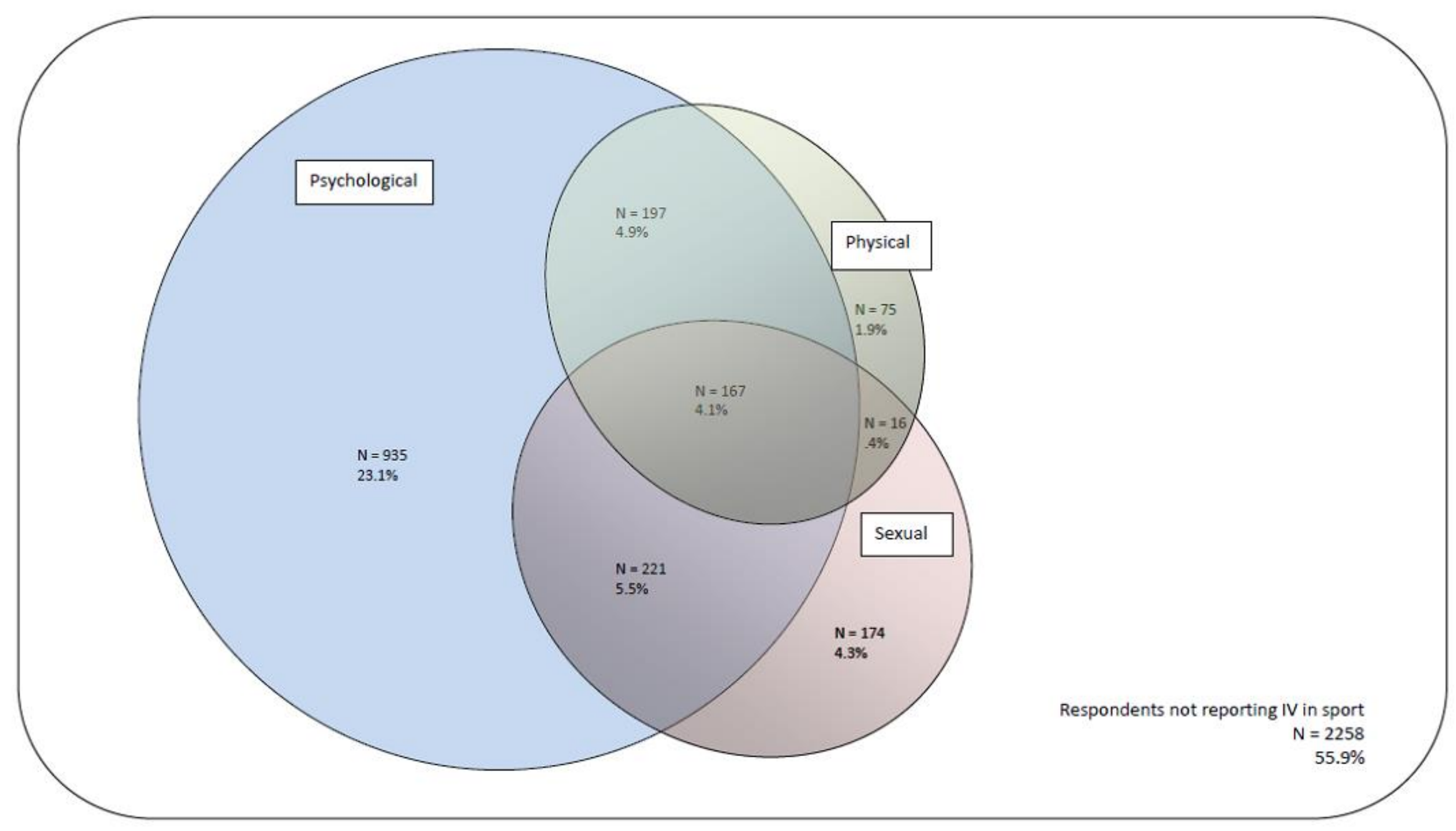




\section{Appendix A}

English rendering of the Interpersonal Violence in Sport (IViS) Questionnaire and the severity classification per item

\begin{tabular}{|c|c|c|c|c|}
\hline & & $\begin{array}{r}\text { Sever } \\
\text { severit }\end{array}$ & $\begin{array}{l}\text { dex: ex } \\
\text { elf-rate }\end{array}$ & $\begin{array}{l}\text { ert-rated } \\
\text { frequency }\end{array}$ \\
\hline & & Once & $\begin{array}{l}\text { A few } \\
\text { times }\end{array}$ & $\begin{array}{l}\text { Regularly/ } \\
\text { Often }\end{array}$ \\
\hline Psych & ogical Violence & & & \\
\hline 1 & You were being teased & 1 & 1 & 2 \\
\hline 2 & You were being bullied & 1 & 2 & 3 \\
\hline 3 & You were put down, embarrassed or humiliated & 1 & 2 & 3 \\
\hline 4 & You were shouted or cursed at & 1 & 1 & 2 \\
\hline 5 & You were negatively criticized about your appearance or weight & 1 & 2 & 3 \\
\hline 6 & You were negatively criticized about your performance & 1 & 1 & 2 \\
\hline 7 & You were called names or otherwise offended & 1 & 2 & 3 \\
\hline 8 & You were ignored such that it made you feel bad & 1 & 2 & 3 \\
\hline 9 & $\begin{array}{l}\text { You were criticized or threatened because you did not want to participate in training sessions or } \\
\text { matches/competitions }\end{array}$ & 1 & 2 & 3 \\
\hline 10 & People were gossiping or telling lies about you & 1 & 2 & 3 \\
\hline 11 & Your belongings were damaged or stolen to humiliate or scare you & 1 & 2 & 3 \\
\hline 12 & You were threatened with being thrown out (of the team, club, gym, etc.) & 1 & 2 & 3 \\
\hline 13 & You were physically threatened, but not actually attacked & 1 & 2 & 3 \\
\hline 14 & You were pressured into / forced to start taking substances to lose weight or enhance your performance & 1 & 2 & 3 \\
\hline Physi & I Violence & & & \\
\hline 1 & You were forced to go on training / playing / competing while you were injured or exhausted & 1 & 2 & 3 \\
\hline 2 & You were shaken & 1 & 2 & 3 \\
\hline 3 & Objects were being thrown at you & 3 & 3 & 3 \\
\hline 4 & You were held / restrained forcefully & 3 & 3 & 3 \\
\hline 5 & You were slapped / hit with an open hand & 3 & 3 & 3 \\
\hline 6 & You were punched / hit with a fist & 3 & 3 & 3 \\
\hline 7 & You were hit with an object (e.g. shoe, racket, hockey stick) & 3 & 3 & 3 \\
\hline 8 & You were forced to the ground / knocked down & 3 & 3 & 3 \\
\hline & & & & 35 \\
\hline
\end{tabular}


1 You were the subject / victim of sexist jokes

You were whistled or yelled at in a sexist way

You were the subject / victim of sexual remarks about your body and looks

You were looked at with an intrusive sexual glance

Your privacy was invaded (someone was standing too close to you, etc.)

There was physical contact that made you uneasy / feel uncomfortable

You were being touched during training in a way that made you uneasy / feel uncomfortable

You were being rubbed or massaged in a way that made you uneasy / feel uncomfortable

You were asked to be alone with someone which made you uneasy / feel uncomfortable

You received calls, notes, emails, texts, photos or clips (possibly on your mobile / the internet)

that had a sexual connotation or were sexually explicit

You received calls, notes, emails, texts, photos or clips (possibly on your mobile / the internet)

that featured you in a compromising or sexually explicit pose or situation

12 You were forced to kiss someone / made to kiss someone against your will

You were asked to undress, assume a sexually explicit pose or perform sexual acts

in the presence of someone (with/without camera) or via social media

14 Someone exposed him/herself to you (in your presence of via social media)

15 Someone touched you sexually against your will

16 Someone tried to have sex with you against your will

You were forced to have sex with penetration (oral, vaginal or anal) 